\title{
POR QUE PLANGEM OS SINOS? RESSONÂNCIAS BIOGRÁFICAS E PATRIMONIAIS NA PAISAGEM SONORA DA CIDADE DE GOIÁS
}

\author{
CLOVIS CARVALHO BRITTO \\ https://orcid.org/0000-0001-6267-544X \\ Universidade de Brasília \\ RAFAEL LINO ROSA \\ https:/ /orcid.org/0000-0001-7918-7792 \\ Secretaria de Estado da Educação de Goiás
}

RESUMO Este artigo analisa as ressonâncias biográficas e patrimoniais dos toques de sino e do ofício de sineiro na paisagem sonora da Cidade de Goiás. Evidencia as reelaborações da secular presença dos sinos dos Passos e da Boa Morte no imaginário dos moradores da cidade, a trajetória do sineiro Benedito de "Sá" Efigênia e o modo como ocorre a transmissão do ofício. O objetivo é compreender a ressonância que os sinos produzem no campo do patrimônio local e como mobilizam narrativas biográficas e autobiográficas a partir dos códigos partilhados socialmente. Para tanto, analisa narrativas elaboradas por memorialistas locais, documentos que integram acervos pessoais e depoimentos de agentes que conviveram com os detentores dos saberes em torno dos toques de sino.

Palavras-chave: Toques de sino. Ofício de sineiro. Patrimônio. Cidade de Goiás.

\section{ABSTRACT WHY DO THE BELLS RING? BIOGRAPHICAL AND}

\section{HERITAGE RESONANCES IN THE SOUNDSCAPE OF THE CITY OF GOIÁS}

This paper analyzes the biographical and patrimonial resonances of the ringing bells and those responsible for maintaining this knowledge in the sound landscape of the city of Goiás. Highlights the representations of the centennial presence of the Passos and the Boa Morte bells in the imagination of the city's residents, the Benedito de "Sá" Efigenia trajectory and the way in which knowledge is transmitted. The objective is to understand the resonance produced by bells in the field of local heritage and how they mobilize biographical and 
autobiographical narratives from socially shared codes. To this end, analyzes the narratives elaborated by the local memorialists, documents that integrate personal collections and testimonies of agents who lived with the knowledge holders around the bell.

Keywords: Ringing bells. Bell ringer. Patrimony. City of Goiás.

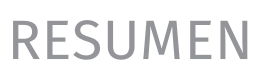

\section{¿POR QUÉ SUENAN LAS CAMPANAS? RESONANCIAS BIOGRÁFICAS Y PATRIMONIALES EN EL PAISAJE SONORO DE LA CIUDAD DE GOIÁS}

Este artículo analiza las resonancias biográficas y patrimoniales de los tonos de llamada de las campanas y los responsables de mantener este conocimiento en el paisaje sonoro de la ciudad de Goiás. Resalta las reelaboraciones de la presencia centenaria de las campanas Passos y Boa Morte en la imaginación de los residentes de la ciudad, la trayectoria Benedito de "Sá" Efigênia y la forma en que se transmite lo saber. El objetivo es comprender la resonancia que producen las campanas en el campo del patrimonio local y cómo movilizan narrativas biográficas y autobiográficas a partir de códigos socialmente compartidos. Con este fin, analiza las narrativas elaboradas por los memorialistas locales, documentos que integran colecciones personales y testimonios de agentes que vivían con los poseedores de conocimiento alrededor del timbre.

Palabras clave: Llamada de las campanas. Campaneiro. Patrimonio; Ciudad de Goiás.

O título deste artigo foi inspirado no título homônimo do poema de Ferreira (2003), cujo questionamento é extremamente pertinente para se pensar a função dos sinos. Nosso intuito é visualizar a importância dos toques de sinos e do ofício de sineiro no imaginário dos habitantes das cidades brasileiras, tendo como estudo de caso as ressonâncias em torno de sua presença na Cidade de Goiás, antiga capital do estado de Goiás. A escolha da cidade se justifica por ser herdeira das configurações do século XVIII e, ainda hoje, manter viva a prática dos toques de sino.

O estudo será apresentado em três movimentos: a presença do "sino dos Passos" no imaginário local; aspectos da trajetória de Benedito de "Sá" Efigênia, o "sineiro da Boa
Morte"; e notas sobre a transmissão do ofício de sineiro. O objetivo é compreender a ressonância que os sinos produzem no campo do patrimônio local e como mobilizam narrativas biográficas e autobiográficas a partir dos códigos partilhados socialmente.

Nesses termos, utilizamos a categoria ressonância de acordo com o entendimento de Gonçalves (2007), quando reconheceu a existência de bens cuja presença nas sociedades extrapolaria o sentido utilitário, evidenciando significados mágico-religiosos e que, portanto, possuem respaldo ou reconhecimento entre a comunidade:

Não são desse modo meros objetos. Se por um lado são classificados como partes inseparáveis de totalidades cósmicas e sociais, por outro 
lado afirmam-se como extensões morais e simbólicas de seus proprietários, sejam estes indivíduos ou coletividades, estabelecendo mediações cruciais entre eles e o universo cósmico, natural e social. [...] Essa categoria de objetos não apresenta assim fronteiras classificatórias muito definidas, sendo ao mesmo tempo objetos e sujeitos, materiais e imateriais, naturais e culturais, sagrados e profanos, divinos e humanos. (GONÇALVES, 2007, p. 214)

Na Cidade de Goiás, os sinos, o vocabulário de motivos e o imaginário por eles acionado, constituem esse tipo de bem, tornando-se "extensões morais e simbólicas" de grande parte de seus moradores e extrapolando as fronteiras. Portanto, investigar suas ressonâncias consiste em evidenciar o modo como constitui subjetividades, por meio da análise de narrativas (auto)biográficas elaboradas por memorialistas locais, da consulta a acervos pessoais e do acesso a depoimentos de agentes que conviveram com os detentores dos saberes em torno dos toques de sino. Para tanto, nosso intuito foi delinear o modo como os sinos de Goiás integram "paisagens sonoras", nos moldes apresentados por Schafer (2001), entendidas como “o nosso ambiente sonoro, o sempre presente conjunto de sons, agradáveis e desagradáveis, fortes e fracos, ouvidos ou ignorados, com os quais vivemos" (p. 367), observando, consequentemente, os efeitos de sua presença na transmissão das heranças culturais locais.

\section{O "sino dos Passos" no imaginário vilaboense $^{1}$}

O grave sino dos Passos derrama na tarde reticências... Talvez expie as culpas seculares dos que morrem devendo penitências. [...]

- Terra minha de opróbrios e martírios! Os sinos da Semana Santa badalam os teus gemidos... (RAMOS JUBÉ, 1984, p. 30)

1 Gentílico dos nascidos no município de Goiás. Remete à Vila Boa, segundo nome da localidade.
Na tentativa de aproximar a Divindade e a Igreja distante, os habitantes dos Goyazes utilizaram as irmandades como pontes estendidas para o desenvolvimento de formas de religiosidade e sociabilidade. Para tanto, solenizavam de modo extremo suas devoções com uma série de ritos e obrigações instituídas em seus compromissos, amalgamando lentamente cultos do catolicismo popular e fazendo circular o sagrado, em determinados momentos, pelo espaço cotidiano. Na urbe que engatinhava, homens e mulheres interligaram a administração colonial com as irmandades e demais símbolos religiosos (santos de devoção, oratórios, capelas, igrejas). O Código de Direito Canônico classificava as associações leigas em Ordens Terceiras, irmandades, confrarias e pias uniões. Moraes (2008) informa que as Ordens Terceiras se inspiravam e eram orientadas por uma Ordem ou Congregação Religiosa, cujas regras de conduta possuíam aprovação da Igreja. Quando as associações se constituíam para exercer obras de caridade, eram designadas de pias uniões e, se possuíssem hierarquias -implicando critérios de seleção e restrição na admissão de seus membros -, recebiam o nome de irmandades. Já as associações formadas para incrementar o culto público de um santo determinado, eram chamadas de confrarias.

Tais atividades eram explicitadas em seus estatutos ou compromissos e poderiam visar, dentre outras coisas, a criação de hospitais, auxílios funerais e enterramentos, além de determinados privilégios na organização e comunhão dos ritos e nas comemorações em louvor do seu orago. Dentre esses momentos, as procissões constituíam oportunidades singulares de demonstração da fé católica em atos de ação de graças, louvor, penitência ou impetração de favores divinos. De acordo com Campos (2005), as irmandades foram instituições pioneiras na difusão e proliferação dos 
ritos do culto da Paixão, com destaque para as do Santíssimo Sacramento, do Senhor dos Passos e da Penitência. Enquanto o clero secular possuía uma atuação que se limitava à celebração dos sacramentos, os leigos foram agentes por excelência de disseminação do denominado "catolicismo barroco", manifesto em suas confrarias. Tais confrarias, segundo Abreu (1994), eram instituídas a partir de irmandades ou ordens terceiras que poderiam reunir membros de distintos grupos sociais, estabelecendo solidariedades verticais, ou servir como associações de classe, profissão, nacionalidade e "cor".

Era nítida uma preocupação pedagógica por parte das irmandades. Na exacerbação de ritos, especialmente cortejos, demonstravam a seus membros o martírio e a redenção dos santos, conjugados a uma reflexão sobre a transitoriedade da vida mundana. As irmandades conquistaram um lugar importante no campo religioso dos setecentos e oitocentos, ao ponto de muitos padres integrarem suas fileiras (por devoção ao padroeiro, obtenção de prestígio, assistência espiritual e/ou controle dos excessos porventura praticados). Moraes (2012) cita, por exemplo, a organização hierárquica estabelecida pelo Compromisso da Irmandade do Senhor Bom Jesus dos Passos de Goiás: provedor, escrivão, tesoureiro, procurador, zelador e doze irmãos de mesa. Além dessa ordem interna, com divisões entre seus membros e estabelecimento de funções e obrigações específicas, as irmandades eram criadas segundo critérios econômicos, sexuais e raciais, assumindo, assim, a característica de um microcosmo social que se insinuava no espaço geográfico.

Na Vila Boa de Goiás - nome anterior da Cidade de Goiás -, por exemplo, existiram irmandades que aceitavam apenas homens brancos - de São Miguel e Almas, de Nossa Senhora da Lapa, do Santíssimo Sacramento e do Senhor Bom Jesus dos Passos -; irmandades que aceitavam apenas negros, homens e mulheres - de Nossa Senhora do Rosário dos Homens Pretos -; irmandades que aceitavam membros de qualquer cor, homens e mulheres, desde que livres - de Nossa Senhora da Boa Morte e de São Benedito -; e irmandades que aceitavam indistintamente brancos, pretos, pardos, crioulos, homens e mulheres, escravizados ou forros - São José dos Quatro Ofícios - (MORAES, 2012). Em 1803, por exemplo, a Irmandade de Nossa Senhora do Rosário reformulou seu Termo, facultando a participação dos brancos em suas fileiras, como podemos verificar no testamento do padre Luís Antônio da Silva e Souza, datado de 8 de abril de 1820: "Nada devendo atualmente às Irmandades de que sou Irmão nesta Cidade que são a do Santíssimo Sacramento, dos Passos, Alma e Rosário, suplico a brevidade dos sufrágios que me devem fazer na forma de seus compromissos" (TELES, 1998, p. 197). O mesmo se valendo para a assistência na morte, já que as sepulturas eram dispostas nos templos e divididas de modo aos fiéis continuarem sob a proteção do orago eleito, como podemos observar na documentação da Irmandade de São Miguel e Almas da Capitania de Goiás, em 1732: "E queriam mais seis tumbas, para animar mais pessoas a entrarem para os Beneficios da Irmandade. [...] Duas do Cruzeiro para cima, duas do Cruzeiro para baixo, mais duas na Sacristia" (BERTRAN, 2002, p. 57).

A Matriz de Sant'Ana abrigava as Irmandades de São Miguel e Almas, do Santíssimo Sacramento, de Sant'Ana, de Santo Antônio dos Militares e Empregados Públicos e a do Senhor dos Passos. A Irmandade dos Passos possuía um altar lateral e um consistório na Matriz e, posteriormente, uma capela própria no lado direito posterior aos altares colaterais, lado da Epístola (MORAES, 2012; MATTOS, 1979). Na verdade, muitos documentos comprovam a 
presença da Irmandade dos Passos e do culto ao Senhor dos Passos em Goiás já na primeira metade do século XVIII, certamente devido à força que possuíam suas congêneres em Portugal e em grande parte dos núcleos urbanos brasileiros do período.

Construídas as primeiras capelas e templos, como de costume, um objeto era essencial ao culto: o sino. Esse objeto, para exercer a sua ação litúrgica de chamada, convocação e avisos deve ser abençoado dentro de um ritual próprio romano:

1032. É costume antigo convocar o povo cristão e adverti-lo dos principais acontecimentos da comunidade local por meio de algum sinal ou som. 0 toque dos sinos exprime de algum modo os sentimentos do povo de Deus, quando exulta ou chora, quando dá graças ou suplica, quando se reúne e manifesta o mistério da sua unidade em Cristo.

1033. Em virtude da íntima relação que os sinos têm com a vida do povo cristão, foi-se impondo o costume, que felizmente se conserva, de os benzer antes de serem colocados no campanário.

1034. Convém suspender ou colocar em lugar adequado o sino que vai ser benzido, de tal modo que, se for conveniente, possa andar-se à volta dele e pô-lo a tocar.

1035. Conforme as circunstâncias do momento e do lugar, a bênção dos sinos faz-se em dia festivo, fora ou dentro da igreja, [...]. Mas se parecer oportuno realizar a bênção dentro da Missa, a bênção faz-se depois da homilia, [...]. Este rito de bênção pode ser utilizado pelo presbítero, que, respeitando a sua estrutura e os seus elementos principais, pode sempre adaptar alguns elementos às circunstâncias das pessoas e do lugar. Se, como é desejável, o bispo presidir à celebração, serão feitas as devidas adaptações. (LEFEVBRE, 1951, p. 397)

Até as mudanças conciliares do século XX, os sinos eram profundamente integrados à comunicação da comunidade. Nesse aspecto, consistem em importante acionador do imaginário. Entendemos “imaginário" como um sis- tema simbólico que se utiliza da linguagem em suas diversas formas, seja por meio do signo linguístico ou por meio de imagens visuais ou de sons, com uma lógica própria. "Imaginário" é um termo que se liga diretamente à atividade da imaginação, uma atividade que, para Ruiz (2004), primeiramente media o nosso contato com o mundo. Essa imaginação é o processar das imagens que primeiro adentram o nosso intelecto: "Por meio das imagens significativas do mundo, vamos tecendo nossa identidade: somos a imagem do mundo, que de modo criativo refletimos em nossa interioridade e projetamos em nossas práxis" (p. 30).

Sinos de igreja, além de seu oficio sagrado, eram e são usados na comunicação de fatos comuns ou emergências: nascimentos, mortes, incêndios, celebrações, visitas de autoridades, entre outros, conforme atesta o Ritual Romano. A Cidade de Goiás possui sinos na matriz e em todas as capelas dentro dos limites urbanos e nos antigos arraiais. Esse instrumento litúrgico alimentou e alimenta o imaginário até hoje, extrapolando o âmbito do religioso e faz parte do dia a dia do vilaboense.

A morte também remete às fragmentações da vida. Por seu caráter inevitável e por ter relação direta com a religião e a cultura, a morte se cerca de símbolos e rituais e de significados que emergem do imaginário. o sino da Igreja de São Francisco de Paula, por exemplo, não plange apenas para as festividades de Passos ou para marcar o meio-dia, na Cidade de Goiás. Anuncia a morte de um irmão ou irmã dos Passos. Quando, em Goiás, se escuta o sino fora de seu horário habitual, sabe-se que um irmão ou irmã faleceu. Coralina (2003), observadora dos acontecimentos do "reino da Cidade de Goiás", comenta em sua crônica "Sinos de Goiás" a respeito dos sons diferentes de seus muitos sinos, atribuindo a cada um deles um significado poético, peculiar, como era comum nas cidades da época colonial. A memória vi- 
laboense refere-se, portanto, ao sino da Igreja da Irmandade dos Passos, presente no imaginário, como algo fúnebre e trágico, quando bate extemporaneamente (ROSA, 2012).

Ninguém aqui desce à cova sem sinal de sino. Já se sabe. Esse, então, varia de Igreja, de bronze e de categoria, [...]. Pode ser irmão: consolo... consolo... consoolooo... chora não... chora não... chora nãoãoão... ${ }^{2}$ [...]. Muito tempo longe de Goiás, passei a desentender a linguagem dos bronzes e querendo me inteirar das ocorrências badaladas, apelo para a instância superior representada por Júlia, com seus 50 anos de Casa Velha e sua comprovada sabedoria do que vai pelo espaço. - Júlia, é anjinho ${ }^{3}$ que estão tocando? - Não senhora, dona Anica, é pecador. - Como assim, Júlia? - O camarim do Senhor dos Passos não toca anjinho, só bate defunto... - É homem ou mulher, Júlia? - É homem, dona Anica; a senhor não vê que é só o grossão? (CORALINA, 2003, p. 15-16).

O "sino dos Passos" está tão arraigado do imaginário religioso vilaboense que se sabe ao seu toque se morreu irmão ou irmã, se vai ter missa ou terço (missa se toca duas vezes, terço apenas uma). 0 ápice do sino se dá no sábado dos Passos, às 15h, quando depois da cerimônia do Encerro, os irmãos mais fortes o tocam exaustivamente e o puxam até ele dobrar dando uma volta de 360 graus, o que é ovacionado e aplaudido pelos presentes. Uma euforia toma os irmãos que cumpriram o seu primeiro dever: avisaram a cidade que seu Cristo, o Cristo dos vilaboenses, se encontra já no seu andor encerrado pelo baldaquim ${ }^{4}$ e pronto para sair da igreja à noite.

2 "Consolo" e "chora não" são onomatopeias que se referem ao som plangente e melancólico do sino, que parece consolar os vivos pela passagem de seu morto.

3 Na cidade de Goiás, "anjinho" ou "inocente" se referem à criança morta e "defunto" ou "pecador" ao indivíduo adulto.

4 Termo de origem árabe arcaico que significaria "cabana". "Armação feita por varões de madeira amarrados nos cantos do andor do Senhor Bom Jesus dos Passos, formando uma espécie de caixote coberto por tecido roxo, com franjas douradas" (SIQUEIRA, 2011, p. 157). Originalmente, era feito de seda e bordado a fios de ouro.
É importante destacar detalhes históricos: o atual sino é do século passado, tendo sido adquirido e mandado instalar em $1925^{5}$ pelo provedor Agenor de Castro. A atual torre sineira, de madeira, foi inaugurada no dia 3 de dezembro desse ano, uma quinta-feira. ${ }^{6} \mathrm{~A}$ história, no entanto, comprova que, antes desse majestoso sino feito especialmente para a Irmandade, outros sinos ali estiveram:

Devido ao estado da Catedral, os Termos de Mesa indicam que em 1870 a Irmandade do Senhor Bom Jesus fez adaptações 'na capela de São Francisco a fim de poder collocar nella a Imagem do mesmo Senhor'. Os documentos também informam que no mesmo ano, em 10 de novembro, foi deliberada a construção 'de uma ligeira torre de madeira com quatro esteios somente travados para se suspender o sino até que se faça a torre'. Questão solucionada em 12 de abril de 1871, com a transferência dos sinos pequenos da Matriz, já em ruínas, para a torre da Igreja de São Francisco (BRITTO, 2011, p. 71).

O texto sugere que a Irmandade possuía seu próprio sino ou demandava posse por um dos sinos da Catedral, em ruínas, já transferida para a Igreja da Boa Morte, e acabou se beneficiando de duas peças colocadas em torre própria. 0 "sino dos Passos" sempre esteve presente nas ações e festividades da Irmandade, não importando onde ele estaria como inquilino, pelos séculos. Isso fica marcado por sua presença no imaginário, conforme emerge na obra do escritor goiano Octo Marques:

Segundo a narrativa de Octo Marques (1977), 'Minervino' fugiu da 'trincheira insalubre', pelo fato de ouvir sem parar um minuto sequer, o 'toque plangente e atormentador do Sino enorme da nossa Igreja de São Francisco, badalando, badalando, sempre tocando e tocando, girando

5 Data gravada no sino.

6 Dados colhidos in loco, em pesquisa na Igreja de São Francisco de Paula. As inscrições com o nome do Provedor que trouxe esse beneficio para a Irmandade encontram-se no próprio sino e em uma plaqueta de metal afixada na primeira coluna direita da torre de madeira, no final das escadas que leva ao sino. 
e girando, naquela cadência tão inesquecivel e que the dilacerava o coração' (p. 46). 0 personagem da história estava na frente de combate brasileira contra os soldados de Solano Lopes na Guerra do Paraguai, mas a memória sonora do tilintar do sino da Igreja São Francisco e a lembrança da proximidade do 'nosso chamado Sábado de Passos' o forçou a se retirar da trincheira tornando-se um desertor. A enunciação do conto sugere a concepção do quanto a memória impera sobre as atitudes psíquicas do ser humano. (BRITTO; PRADO, 2011, p. 105)

A Guerra do Paraguai durou de 1864 a 1870. A Irmandade dos Passos encontrava-se já, com o santo, na Igreja de São Francisco de Paula, a usar, nas suas procissões, o seu enorme e plangente sino, anterior ao que se encontra lá, certamente de dimensões parecidas. Esse sino anterior, ainda do século XIX, é que tocou na imaginação do soldado desertor (ou na imaginação do autor do texto?). Mas quantos sinos a Irmandade teve? Provavelmente vários até a data do erigir-se de sua torre própria, em 1925. Os sinos usados eram os da Catedral, ou da Igreja onde a Irmandade estivesse, ou eram os requisitados ao bispo por doação. No entanto, isso não diminui a importância do sino e nem impede a integração de sua imagem sonora ao imaginário local.

Em 2015, retomou-se em Goiás o costume de abrir a Igreja de São Francisco de Paula todas as sextas-feiras, para reza do terço e retomada do costume de se ir visitar a imagem para "beijá-la", conforme uma antiga prática que estava relacionada também à sociabilidade e à vida comum dos vilaboenses, conforme atestam Britto e Prado (2011), falando das devoções religiosas na passagem dos séculos XIX para XX: "Não sem motivos, a participação em confrarias e irmandades garantia um enraizamento e promovia a sociabilidade dos habitantes dos sertões dos Guayazes, além de conferir notabilidade e prestígio para seus membros" (p. 109). Esse ato de beijar o Senhor dos Passos era uma espécie de forma de devoção popular, realizada pela Irmandade e sem vínculos com a atividade oficial diocesana, mas popularmente realizada, como atesta a biografia de Anna Joaquina Marques e Joaquim Craveiro de Sá (BRITTO; PRADO, 2011).

A Igreja de São Francisco é aberta à visitação, de terça a domingo, no período vespertino. Como toda atividade religiosa da Irmandade, começa a reza do terço com o sinal sonoro de chamamento: o toque do sino. Para alguns irmãos e irmãs, ouvir esse sinal já é o suficiente para irem à Igreja munidos de suas murças e balandraus,7 perguntando pela missa. Um dos registros da pesquisa de campo marca um evento inusitado: uma vilaboense passante, preocupada, indagou quem houvera morrido naquele dia, ao ouvir o sino, legitimando uma das muitas facetas da semântica do sino dos Passos: anunciar o óbito de um de seus irmãos ou irmãs.

A respeito disso, o sino tem a centralidade na composição dessa narrativa do imaginário vilaboense: ouviu-se o sino de Passos, é festa, é missa, é morte, é tragédia. A irmandade dos Passos, como agente acionador do imaginário quaresmal nunca prescindiu do uso de sinos, usando toques próprios à sua liturgia quando na Catedral e depois com a obtenção do majestoso sino dos Passos de bronze puro, ao tocar em três ocasiões somente: atos religiosos, toques fúnebres e algumas festas civis como aniversário da cidade, transferência temporária da capital de Goiânia para Goiás.

A farta documentação consultada por Britto (2011) demonstra que a posse da Igreja de São Francisco pela Irmandade dos Passos não aconteceu de modo imediato, mas representou uma lenta e gradual retirada da Irmandade da circunscrição da Catedral marcada por saídas e retornos. A caminhada do Senhor dos Passos

7 Vestimentas roxas das irmãs e irmãos dos Passos, respectivamente. 
incluiu idas e vindas, referindo-se ao itinerário de suas sedes provisórias até se chegar à sede definitiva: da Matriz de Sant'Ana para a Igreja de Nossa Senhora do Rosário, de lá para a Igreja de Nossa Senhora da Lapa e, por fim, sua retirada para a Igreja de São Francisco de Paula. Essa estada fez com que, vagarosamente, a Irmandade fosse adaptando o templo às suas necessidades: modificações internas no altar, múltiplas construções e reconstruções do camarim da imagem etc. Essa apropriação foi lenta: da deliberação da ida solene por procissão da Lapa à São Francisco em 1833 até a construção da torre própria com sino personalizado, trazendo o nome da Irmandade em 1925, foram longos 92 anos, quase um século.

Figura 1 - Detalhe do sino dos Passos.

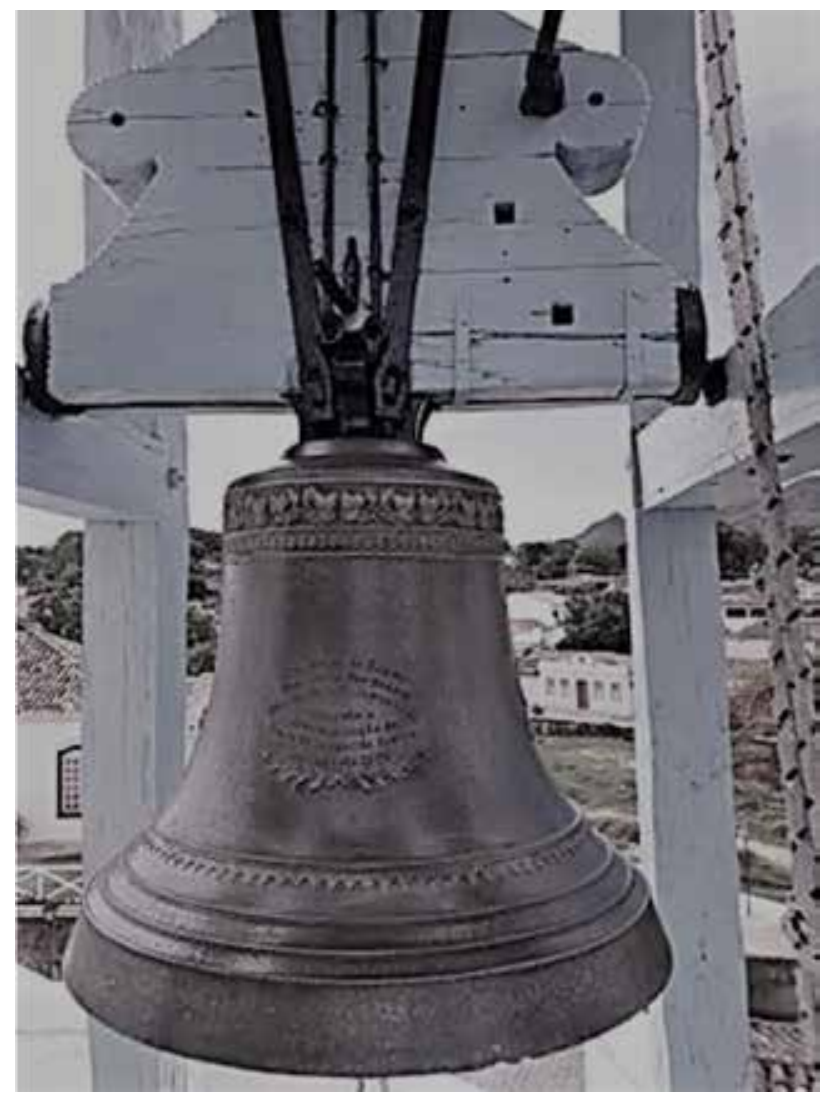

Fonte: Clovis Britto, 2019.

O Estatuto datado de 2005 faz referência à saída da Catedral em data bem anterior ao século XX, marcando para isso o ano de 1870. Tamaso (2007) marca essa saída para 1873. No entanto, a pesquisa realizada para as publicações e estudos de Britto (2011) e Rosa (2012) fornecem outra visão: uma visão de itinerância, de deslocamentos físicos, geográficos, um périplo da Irmandade, indo e vindo - movimento que inclui cruzar pelo menos uma vez o Rio Vermelho -, instalando-se aos poucos e modificando a capela para que ficasse cada vez mais adequada a imagem do Senhor dos Passos, ${ }^{8}$ algo que durou mais de nove décadas e passou por dois séculos. A construção da torre definitiva e a instalação de um sino com o nome da Irmandade dos Passos em 1925 marca essa posse simbólica e concreta como definitiva, sendo tombada pelo Instituto do Patrimônio Histórico e Artístico Nacional (IPHAN) ao compor os bens móveis e integrados da Igreja de São Francisco de Paula, em 1950. ${ }^{9}$

Na verdade, o sino dos Passos em sua cultura material se torna sintese - metáfora e metonímia - das ressonâncias em torno do imaginário que aciona. Desse modo, a "linguagem do sino", por meio de seus toques, aciona uma semântica, vocabulário de motivos compartilhado entre os moradores de Goiás: "Sino dos Passos, / Teu badalar sonoro/ ao ressoar plangente,/ Dolente/ [...] São farpas de saudade, agudas e pungentes/ Ferindo sem maldade/ 0 coração da gente!/ [...] É a saudade/ Refletindo-se no espelho. Das emoções; / É o acalanto/ De todos nós" (SOUZA FILHO, 1981, p. 30).

\section{Benedito de "Sá" Efigênia: reverberações do "sineiro da Boa Morte"}

8 Segundo as narrativas tradicionais a imagem do Senhor Bom Jesus dos Passos da cidade de Goiás teria sido trazida da Bahia ainda na primeira metade do século XVIII. A escultura em madeira mede $1.99 \mathrm{~cm}$ e carrega uma grande cruz e, o que se comprova, é a sua presença em 1749, conforme atestam documentos avulsos da Capitania de Goiás (BRITTO; ROSA, 2011).

9 Inscrita no Livro do Tombo de Belas Artes, volume I, folha 73 , número de inscrição: 360. 
Benedito de Efigênia, o sineiro da Boa Morte, veterano nessa profissão, que era privilégio seu, desde tempos remotos. Dão... dão... dão... choram os sinos da antiga igreja; choram a morte daquele que os visitava diariamente no momento exato: pela manhã, ao meio dia, à hora do Ângelus ou quando algum oficio religioso extraordinário devia realizar-se. Por seu intermédio, aqueles sinos se tornavam mensageiros de júbilo, repicando alegremente, em ocasiões festivas ou mensageiros de amargura, dobrando afinados, quando a morte visitava a cidade. (FERREIRA, 2003, p. 85-86)

O "sino dos Passos" assume protagonismo no imaginário vilaboense, especialmente por mobilizar um feixe de símbolos em torno da dor e do sacrifício (ROSA, 2016). O sino se torna, nesse aspecto, um mediador das mensagens entre os fiéis e o padroeiro, ao ponto de, ele próprio, por meio de sua sonoridade, ofuscar a trajetória dos sineiros responsáveis por mobilizar e dar sentido a gramática de sonoridades. Isso é evidente em diversos poemas e crônicas que descrevem a importância do "sino dos Passos" no imaginário vilaboense. Nenhum desses registros evidencia o nome dos sineiros responsáveis pelo ofício, ao contrário, utilizam a figura de linguagem prosopopeia ou personificação para sugerir a ação “autônoma" dos "bronzes" (RAMOS JUBÉ, 1984; SOUZA FILHO, 1981).

Em contraposição, os textos sobre o "sino da Boa Morte", fundido em Goiás em 1785, evocam a presença do sineiro Benedito de "Sá" Efigênia. O que teria contribuído para que o sineiro escapasse dos silêncios da história como ocorreu com seus colegas de ofício? Seria o fato de sua morte coincidir com o período de desativação da Igreja para a transformação em museu de arte sacra, tornando-o símbolo do oficio na medida em que não era mais possivel traduzir sua linguagem sonora? Sua longa presença no ofício, atravessando o final do século XIX até a

10 Data gravada no sino. segunda metade do século $X X$ ? Ou sua atuação personalíssima mobilizaria, por meio da "linguagem" dos sinos, um imaginário que tocava a sensibilidade de seus contemporâneos?

Figura 2 - Sino da Boa Morte.

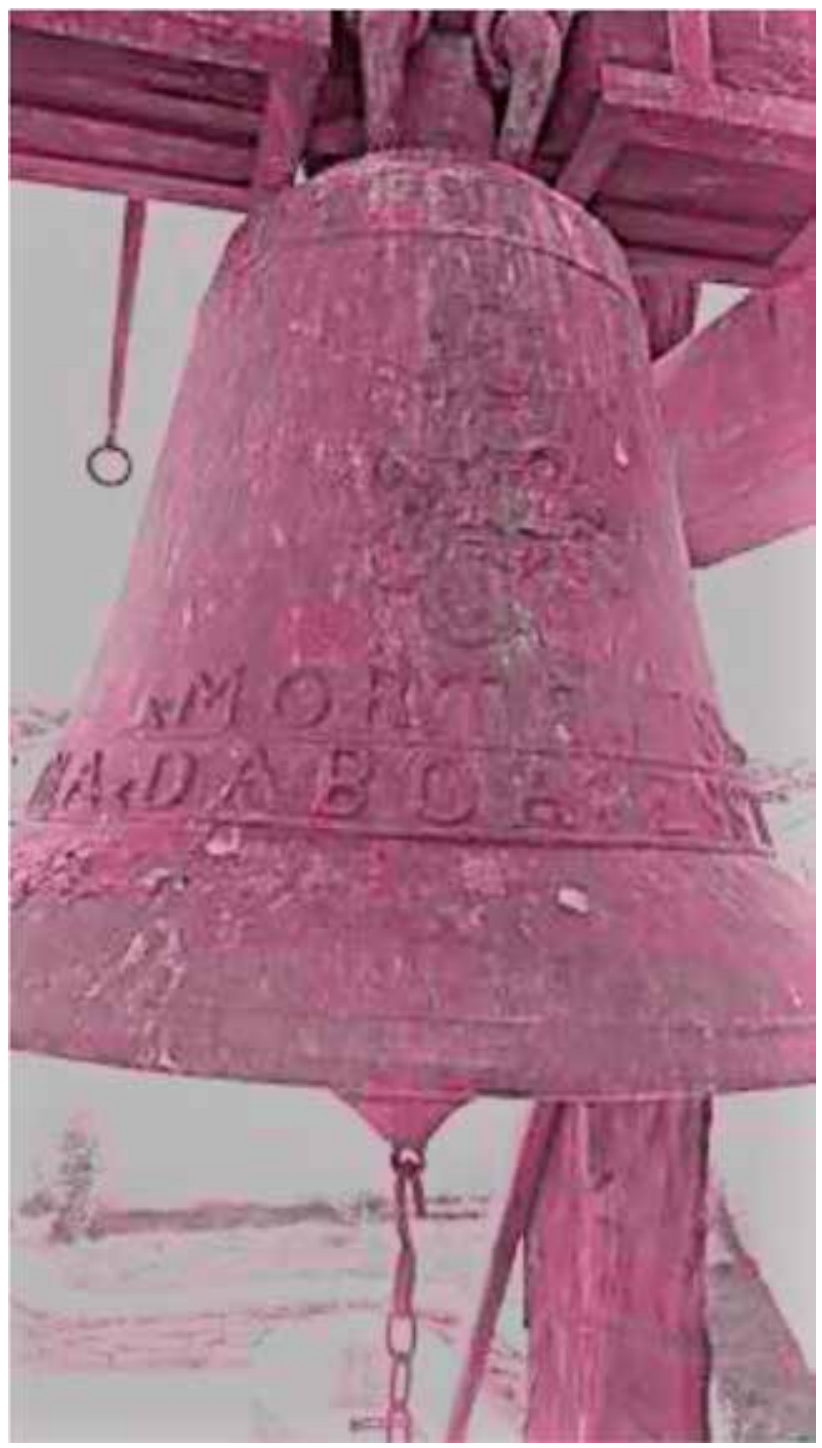

Fonte: Rafael Lino Rosa, 2019.

A epígrafe consiste em um trecho da crônica de Ferreira (2003) escrita como necrológio a Benedito de Sá Efigênia. A autora constrói a imagem do sineiro a partir de sua intrínseca relação com o "sino da Boa Morte", destacando sua habilidade e singularidade ao conferir uma espécie de "gramática" de sonoridades, sendo inventor de muitos toques:

Conhecia muito bem a linguagem do bronze, qual famoso maestro conhece os instrumentos 
componentes de sua orquestra. Os diversos toques eram como trechos de uma partitura: 'Vira Mingau', mais dificil que requeria o uso de uma corrente presa ao ombro, destinada à manobra do sino grande, ficando as mãos para os menores. 'Vaga-Lume Cai, Cai', toque cotidiano; 'Moacir', repiques vibrantes dos dias festivos. Finados: para o sexo masculino, sino maior primeiro; para o feminino, sinos menores antes; para anjinhos, só repiques dos pequenos (p. 86).

A crônica de Di Guimarães (2000), além de evocar a perícia de Benedito de "Sá" Efigênia, acrescenta o fato dele ser negro, solteirão, "de idade mais ou menos indefinível, falando muito pouco, pobre e prestativo" (p. 105). Também reconhece o sineiro como responsável por costurar/conter o tempo, anunciador de ritos de passagem, marcador simbólico do calendário religioso, afetivo e mítico da cidade:

Põe ele toda inspiração, que mora em sua alma simples, em fazer dobrar em sons, que podem ser lamentos e podem ser aleluias, o velho sino da igreja que se perfila ao lado do 'Conde dos Arcos'. Se quatro velas se acendem, iluminando o marfim de um anjo morto, incapazes de se apagar ao peso das lágrimas de uma mãe que perdera o filhinho, é o Benedito que faz soar o sino, na piedosa tradição do 'sinal'. E o som do bronze tem uma música alegre, congratulandose com o Céu, por mais esse anjo que fora enriquecer a sua legião de eleitos. Se um pai ou uma mãe atendem ao chamado do Senhor, deixando, cá embaixo, os entes que não compreendem bem os altos desígnios de Deus, é, ainda, ele quem movimenta o sino anunciando que um justo subiu ao Céu. Quando dois entes que se amam vão trocar, no altar, o beijo do 'conjugovobis', o sineiro deixa o sino e vai levar cravos ao altar. Nas tradicionais Folias do Divino, soam os sinos com suaves sonoridades de aleluias. Nas procissões, quando a alma católica da gente de Vila Boa se ajoelha ante o esquife de um Deus morto que desfila diante da humanidade que agoniza, é o Benedito quem segreda ao bronze a gravidade da hora (DI GUIMARÃES, 2000, p. 106).

$\mathrm{Na}$ verdade, é significativo destacar a centralidade que a Igreja de Nossa Senhora da Boa
Morte possuía na Cidade de Goiás enquanto Catedral provisória desde 1871 em virtude do estado de ruínas que se encontrava a Catedral de Sant'Ana, ocupando essa função até 1967 (BRITTO, ROSA, 2017).

Na transição dos séculos XIX e XX, centramse na Igreja de Nossa Senhora da Boa Morte, que servia de Matriz e Catedral de Goiás, as devoções marianas mais importantes da cidade, seguindo um ciclo litúrgico próprio, porém carregado de elementos paralitúrgicos teatralizados com efeito catequético. A grande preocupação dos curas e monsenhores, nesses momentos, era realizar um auto de fé que servisse como uma catequese fixadora das doutrinas e dos dogmas, por um lado, e reativadora do imaginário religioso, por outro. Na Igreja da Boa Morte,11 destacavam-se festas ao longo de todo o ano, marianas, que impactavam os habitantes da cidade (Nossa Senhora das Graças, Nossa Senhora da Boa Morte, Nossa Senhora da Glória, Nossa Senhora das Dores, Nossa Senhora da Conceição, Nossa Senhora das Vitórias etc.), além das missas, comemorações da Semana Santa, Corpus Christi, Natal e da festa da padroeira Sant'Ana. Isso significa que os sinos do campanário da Boa Morte eram os mais mobilizados ao longo de todos os dias do ano e, portanto, exigia do sineiro um vasto acervo de toques específicos para cada uma das solenidades:

11 A Igreja de Nossa Senhora da Boa Morte foi concluída em 1779 pela Irmandade dos Homens Pardos. Em Goiás, o primeiro termo de compromisso da Irmandade de Nossa Senhora da Boa Morte data de 1774, organizada pelos homens pardos e que em todos os anos promovia uma solene procissão. Essa procissão alcançou a primeira metade do século XX, mesmo com o fim da irmandade. Era realizada uma solene procissão fúnebre, com a imagem de Nossa Senhora de mãos postas deitada num esquife. No dia 15 de agosto, em diversas cidades brasileiras fazia-se a mesma procissão com a mesma imagem vestindo outras roupas, para se comemorar a Assunção de Maria. A festa da Assunção era um importante evento, solene, cuja prática na Cidade de Goiás está justificada pela presença de uma capela a Nossa Senhora da Boa Morte. Após a procissão representando a morte, em 15 de agosto era realizada outra procissão, em louvor a Assunção e que em Goiás era cultuada como Nossa Senhora da Glória. 
Pachorrentamente, Benedito de Figênia subiu os degraus da escada da torre dos sinos da Igreja da Boa Morte, em Goyaz. Um sino grande e dois pequenos. Era o momento de tocar a primeira vez para a missa matutina, num dia de preceito. Prendendo no braço esquerdo a corda do badalo do sino grande e com os badalos dos sinos pequenos em cada mão, iniciava o sineiro o repique, fazendo onomatopeia do 'Vaga-lume cai cai': Blém, blém, bão... blém, blém, blém, blém, bão...blém, blém, blém, blém, bão... E o som afinado dos sinos era ouvido em toda a cidade, ecoando nas serranias distantes. Quinze minutos após, um novo repique. Afinal, o sino grande badala a chegada do padre ao altar: bão... bão, bão bão bão, bão... Era o início da santa missa. Às doze e às dezoito horas de todos os dias do ano, o sino grande, com suas badaladas compassadas, alertava os fiéis a hora do Ângelus. (SOUZA FILHO, 1981, p. 18)

Essa "gramática de sonoridades" traduzia para os vilaboenses um conjunto de informações ao longo de todo ano. Partindo do calendário litúrgico, os sinos também marcavam - e ainda marcam - o tempo cronológico, mítico e ritual daquela comunidade. De acordo com o toque, é possivel aferir, por exemplo, se alguém morreu e se é homem, mulher ou criança. De acordo com a sonoridade, é possivel identificar em qual das igrejas ou instituições estão ecoando as mensagens e, por exemplo, onde será realizada a missa ou o toque de recolher.12

De acordo com Souza (2015), os sinos vilaboenses não possuem nomes próprios, adquirindo o nome de suas igrejas: "a eles foi dada a propriedade de humanizar-se, conferindo-se aos toques o atributo da vocalização." (p. 195). Informa ainda que, em seus toques básicos dobre simples, dobre duplo e repique -, não se diferencia de outros toques de qualquer cidade, se individualizando em decorrência das especificidades e dos detalhes de cada toque:

12 O sino da Casa de Câmara e Cadeia, por exemplo, anunciava o toque de silêncio da noite, alarmes em casos de incêndios e enchentes e o julgamento de presos (SOUZA, 2015). “pode ser anjo com seu toque argentino: stá no céu... stá no céu... sta no céu... coitadim... coitadim...coitadiiinho... Pode ser irmão: consolo... consolo... consoolooo... chora não... chora não... chora nãoãoão [...]" (CORALINA, 2001, p. 15).13

Todavia, é oportuno retomar alguns questionamentos: se em todas as seis igrejas existentes na cidade de Goiás ao longo da primeira metade do século XX existia esse ritual de sinos que, em alguns casos tocavam simultaneamente, por que de todos os sabedores deste ofício o nome de Benedito de "Sá" Efigênia sobreviveu com tamanha força nos registros dos memorialistas e na memória dos mais velhos da cidade? o que ele mobilizou que resultou na sobreposição da sua imagem à do próprio "sino da Boa Morte"?

Figura 3 - Benedito de "Sá" Efigênia na torre sineira da Igreja da Boa Morte (Autor e data não identificados).

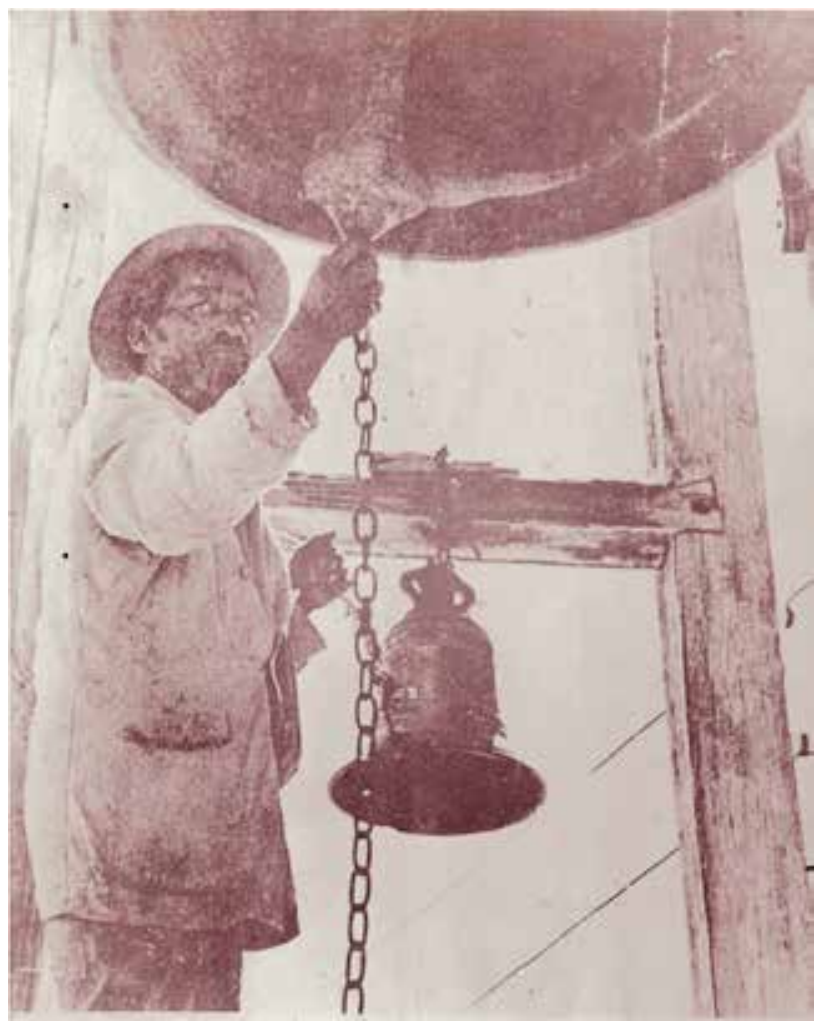

Fonte: acervo de Clovis Britto.

13 Ana Guiomar Souza (2015) sublinha que "os sons chamados argentinos são agudos como a voz das crianças. Já as palavras atribuídas aos adultos mortos pressupõem o grave da voz masculina ou a tessitura média da voz feminina" (p. 195). 
Uma das hipóteses já delineadas consiste na própria centralidade que a Igreja da Boa Morte possuía no cenário religioso vilaboense enquanto Catedral provisória. Mas esse argumento isolado não justificaria a argumentação, em decorrência do papel que a Igreja de São Francisco e a Venerável Irmandade do Senhor Bom Jesus dos Passos também ocupam no imaginário vilaboense. Na verdade, creio que a este fato somam-se duas outras questões: Benedito de "Sá" Efigênia ter sido o sineiro que mais tempo desenvolveu seu oficio - mais de sessenta anos ininterruptos - e sua atuação personalíssima ao ponto de criar toques particulares:

Igreja da Boa Morte - Há mais de meio século Benedito de Sá Efigênia tem a função de sineiro oficial desta igreja. É ele quem toca as badaladas do meio dia, o 'angelus', as chamadas para as missas, os sinais de morte e enterro, os dobres da Paixão e da Aleluia. Benedito se diz criador de muitos 'toques', além dos que aprende com seu antecessor e mestre [...] quando criança. (LACERDA, 1977, p. 44)

Em conversas com contemporâneos de Benedito de "Sá" Efigênia, são recorrentes as lembranças de seus toques inconfundiveis, permitindo aos moradores não apenas identificar a "linguagem dos sinos", mas seu autor, tamanha a personalidade que imprimia no ofício. Isso se traduzia no modo como operava o ofício e aos toques que imprimia forte assinatura sonora. Desse modo, ele se tornou uma ponte entre o século XIX e o século XX, preservando o que aprendeu com os mestres sineiros que $o$ antecederam e marcando o ofício com sua assinatura inconfundivel, tornando-se um artista que soube, como ninguém, extrair os sons dos sinos.

A folclorista Regina Lacerda (1977) não conseguiu identificar o nome do sineiro que ensinou Benedito de "Sá" Efigênia o ofício, sublinhando que o mesmo aprendeu ainda na infância esse saber, em fins do século XIX. Essa dificuldade diz respeito ao fato de que, assim como ocorreu em muitas cidades de Minas Gerais, o ofício de sineiro era realizado na maioria das vezes por negros escravizados:

Aluízio Viegas reitera a existência de muitos negros, mulatos, pardos e alguns escravos alugados para os serviços do toque dos sinos. Ele citou o caso de Ana Romeira do Sacramento, que alugava um escravo de nome Francisco para tocar os sinos na Matriz do Pilar em São João del -Rei. Segundo ele, depois da abolição, o trabatho de tanger os sinos ficou a cargo das pessoas mais simples que se subordinavam às mesas administrativas dos sodalícios da região. Ainda segundo Aluízio Viegas, o fato desse oficio ser desempenhado por pessoas das camadas mais pobres da população não significa que as torres não fossem frequentadas por pessoas de todas as camadas sociais. Há referência também que capoeiras e escravos se escondiam nas torres das igrejas onde ninguém ousava subir. Tanto hoje como outrora, os espaços das torres são espaços de liberdade. Liberdade de criação, inclusive. (BRASIL, 2009, p. 39)

No caso da cidade de Goiás, é provável que este ofício ao longo dos séculos XVIII e XIX também tenha ficado a cargo de escravizados ou pessoas de camadas mais pobres. Em pesquisa nos jornais goianos Correio Official de Goyaz e Goyaz, foi possivel identificar o nome de Manoel Benedito de Lima que atuou como sineiro da Catedral (e, na segunda metade do século XIX, da Boa Morte). O mesmo teria realizado o oficio desde a mocidade, falecendo com mais de 80 anos em 1887. Manoel foi substituído por José Claro que permaneceu apenas cinco anos como sineiro da Boa Morte, falecendo em 1891.

$\mathrm{Na}$ verdade, não foi possível identificar o sineiro que ensinou o ofício a Benedito de "Sá" Efigênia. Certamente algum dos sineiros que mobilizavam as torres das muitas igrejas de Goiás na última década do século XIX ou na primeira do século XX. Apesar das poucas referências sobre sua vida pessoal, os depoimentos coletados informalmente reafirmam que 
ele teria apreendido o ofício na infância, sendo órfão de pai e filho de uma ex-escravizada de nome Efigênia do Rosário, aliás sua alcunha remete ao nome da mãe: o "Sá" não é sobrenome, mas um apócope do termo "sinhá", Benedito - filho de sinhá Efigênia. Solteiro, residiu na Rua da Carioca com a mãe idosa e atuou como zelador e sineiro da Igreja da Boa Morte até a década de 1960. Os informantes destacaram que ele utilizava sempre um terno branco e que ele também atuava como fogueteiro.

Seu atestado de óbito informa que seu nome era Benedito Efigênio do Rosário (nome que reúne três devoções comuns às irmandades negras), nascido no ano de 1891, na cidade de Goiás, de filiação ignorada, e falecido no Asilo São Vicente de Paulo em 19 de novembro de 1970.0 ofício de sineiro não foi mencionado no documento, sendo registrado como "indigente" no item profissão. ${ }^{14}$

A torre sineira da qual Benedito era guardião compõe os bens móveis e integrados da Igreja de Nossa Senhora da Boa Morte, tombada pelo Iphan em $1950^{15}$. As ações da patrimonialização e a inserção da cidade de Goiás no roteiro turístico alteraram o cotidiano da população vilaboense (TAMASO, 2007). Certamente, um dos principais impactos na vida de Benedito de "Sá" Efigênia foi a transformação da Igreja de Nossa Senhora da Boa Morte em Museu de Arte Sacra da Boa Morte, o que implicou em outros usos e, consequentemente, na gradativa aposentadoria do sineiro. No mesmo período, a Catedral de Goiás voltou para a Igreja de Sant'Ana ainda inacabada. A igreja não possuía sino, fato que demonstra uma mudança de prioridades, sendo utilizado esporadicamente o sino da torre da Boa Morte como sino da Catedral. Essas alterações coin-

14 Registro no 6.536 do livro de óbitos de 1969-1973 do Cartório de Registro Civil e Tabelionato de Notas da Cidade de Goiás-GO.

15 Inscrita no Livro do Tombo de Belas Artes, volume I, folha 72, número de inscrição: 356. cidiram com a velhice e doença de Benedito de "Sá" Efigênia, cujo corpo não mais atendia ao chamado dos sinos. Talvez, por essa razão, a memória em torno de Benedito esteja tão presente ainda hoje na cidade de Goiás, tendo sido o mais longevo, o mais criativo e o último "sineiro da Boa Morte".

\section{Os sinos, os sineiros e os toques: notas sobre a transmissão do ofício}

Os sinos, então, conjugados por autênticos sineiros que cresceram nas torres, falam, chamam, soluçam, plangem. São argentinos, graves, fúnebres e dolentes, numa escala cromática de sons harmonizados ou díspares que rolando pelo espaço vão se perder nas quebradas distantes da serrania imensa, levantando os corações para o alto. A gama sonora vai do pequeno toque ao grande dobre e é a entrada, o sinal, a procissão. Procissão saindo, procissão entrando. Reza. Missa. Novena. Tríduo. Missa solene com seu toque repetido e festivo. Repiquete no Carmo. Dobre na Abadia. A cidade acorda com os sinos... são as matinas. A do Rosário avisa com 23 pancadas. A Boa Morte, quando o sineiro está em dia, responde com 94 badaladas. Trindades ao meio-dia e vésperas pela tarde. Ninguém aqui desce à cova sem sinal de sino, já se sabe. Esse, então, varia de Igreja, de bronze e de categoria (CORALINA, 2003, p. 14-15).

A presença dos sinos, dos sineiros e dos toques consistem em importante acionador do imaginário vilaboense, a exemplo do que destacamos nos casos dos sinos dos Passos e da Boa Morte. Todavia, esse imaginário é mobilizado nas diversas igrejas erigidas na Cidade de Goiás e que, conforme o trecho da crônica de Coralina (2003), utilizado na epígrafe, estabelecem uma gama sonora, um vocabulário compartilhado e um conjunto de histórias em torno do ofício. Uma das mais famosas consiste na queda da torre da Igreja de Nossa Senhora da Lapa, em decorrência da enchente de 1839. 
Visando alertar a cidade, o sineiro teria tocado o sino e morrido tragado pelas águas do Rio Vermelho:

A igreja rodou. 0 sineiro estava na torre tocando, tocando... dando aviso do perigo, pedindo rezas. 0 povo de longe gritava, fazia sinais que descesse e ele nada de ouvir, só queria tocar. Já tinham tirado as alfaias e as imagens. $O$ homem do sino não deu fé do perigo e lá se foi a igreja arrancada, torre e sineiro rodaram rio abaixo, o sino tocando mais. Afinal, a igreja se abriu de todo, no lugar da Pinguelona, onde o sino ficou encalhado e o sineiro se achou depois, cheio d'água, agarrado ao badalo. Gente que mora ali perto conta que terça à noite, ainda se ouve o sino tocar, isso quando a cidade se aquieta e as águas ficam dormindo. $\mathrm{E}$ a alma do sineiro nunca se afastou do lugar. Aparece em grandes visagens, muito alta e muito branca, crescendo e minguando, aparecendo sobre as águas, se sumindo de repente, repousando nas pedras, esperando que o povo tire o sino debaixo d'água e o reponha no alto de sua torre. (CORALINA, 1989, p. 31-32)

O fato é que os sinos povoam o cotidiano dos vilaboenses, acionando um imaginário que atravessa os sentimentos de dor e sacrifício, mas também marcado por júbilos. 0 sineiro foi capaz de dar sua vida pelo ofício e, mesmo morto, continuou guardião do sino e da cidade. No caso do incêndio da Igreja da Boa Morte, em 1921, os sinos também foram os mensageiros da tragédia (PASSOS, 1986).

Nesse aspecto, os toques de sinos consistem em códigos compartilhados entre os sineiros e a comunidade, a comunidade e a Divindade, e os moradores são os responsáveis por decodificar e transmitir para os mais jovens essas informações. Isso pode ser visualizado no caso de Cora Coralina que, vivendo 45 anos fora de Goiás, teve que reaprender a "linguagem dos bronzes": "Muito tempo longe de Goiás, passei a desentender a linguagem dos bronzes e querendo me inteirar das ocorrências badaladas, apelo pela instância superior representada por Júlia, com seus 50 anos de Casa Velha e comprovada sabedoria" (CORALINA, 2003, p. 15).

A necessidade de preservação desses saberes de interferências outras que possam colocar em risco a continuidade do código compartilhado pode ser visualizada em diversos exemplos. É comum turistas desavisados subirem nas torres sineiras e desejarem badalar os sinos. Há na cidade uma vigilância constante para que os sinos não sejam tocados aleatoriamente, informando mensagens de modo equivocado. Desse modo, o toque dos sinos exige não somente ocasiões específicas, mas pessoas previamente preparadas.

Exemplo instigante consiste na Igreja de Nossa Senhora do Rosário. O carrilhão da torre do Rosário se tornou o "relógio" e seus sinos os "afilhados"16 dos vilaboenses. Em 2017, um novo frei decidiu retirar a marcação dos sinos que badalavam na torre a cada $15 \mathrm{mi}$ nutos, nos quartos de hora, e cuja sonoridade alcança grande parte da cidade. O religioso extinguiu os toques a cada 15 minutos e as badaladas marcando as horas alegando falta de pessoal para dar corda, falta de peças e de pessoas qualificadas para afinação. Inúmeras reclamações povoaram o cotidiano da cidade em virtude dos silêncios do "sino do Rosário", cujo silenciamento consistiu em uma violência simbólica (BOURDIEU, 1998) para gerações de vilaboenses. Em 2019, com a mudança do religioso, outros freis deram corda no relógio e reintegraram os toques à paisagem sonora: “O relógio dos frades/ martela horas./ Sinos tocam a entrada" (CORALINA, 2001, p. 125).

16 Fundada em 1734 pela Irmandade dos Homens Pretos, a Igreja de Nossa Senhora do Rosário foi demolida e reconstruída em 1943 pelos padres dominicanos. Em sua inauguração, muitos vilaboenses foram padrinhos e madrinhas dos sinos, conforme relatou Iracema $\mathrm{Ma}$ lheiros em depoimento a Tamaso (2007): "Eu fui com meu tio e minha tia e eles seguraram na fita, porque todo mundo foi padrinho dos sinos, que era uma fita que vinha lá dos sinos e como se eles tivessem puxando e batendo na inauguração da igreja" (p. 615). 
Na Cidade de Goiás, é urgente um trabalho de preservação e valorização do ofício de sineiro e dos toques de sinos, especialmente quando reconhecemos que a maioria dos sabedores do ofício está envelhecendo e morrendo sem transmitir esse legado. Uma tentativa de preservação e que poderia inspirar os vilaboenses consiste no registro dos toques de sinos de Minas Gerais e do ofício de sineiro como patrimônio imaterial nacional (BRASIL, 2009). O dossiê que instruiu o registro em 2009 reúne farta documentação sobre o oficio e, guardados os diferentes contextos, em muito se aplica ao caso goiano e vilaboense. Um dos interessantes dados consiste nas formas de transmissão, preservação e decodificação em torno da arte de "fazer falar os sinos" como forma de pertencimento:

As informações obtidas durante a pesquisa de campo nas cidades inventariadas nos informam que grande parte da população dessas localidades identifica a sonoridade dos sinos de cada igreja, o que nos leva a considerar não apenas a estrutura dos toques, mas, especialmente, a sonoridade de cada um dos sinos. Entretanto, sonoridade e estrutura se complementam. [...] A pesquisa mostrou também que o toque dos sinos, expressão sonora que confere significado cultural ao território inventariado, resulta e é indissociável do saber do sineiro, o qual envolve habilidade e conhecimento apurados em séculos de história e dele exige dedicação de devoto ou de profissional. As diferentes experiências pessoais de reconhecimento e apropriação do universo dos sinos asseguram aos habitantes das localidades alcançadas por este estudo um sentimento de pertencimento e lhes confere uma territorialidade específica (BRASIL, 2009, p. 33-34).

O dossiê destaca as orientações sobre os toques de sinos no Brasil Colônia reguladas pelas Constituições Primeiras do Arcebispado da Bahia, de 1707, e classifica os toques a partir do ritmo - festivos, fúnebres e cotidianos - e da execução - repiques e pancadas, com o sino paralisado; dobres simples ou duplos, com o sino em movimento.

Na Cidade de Goiás, além de Benedito de "Sá" Efigênia, que era responsável pelo "sino da Boa Morte", se destacaram sineiros ao longo do século XX que desenvolveram sua arte nas outras igrejas, em especial na Igreja de São Francisco de Paula: o português Alfredo Francisco dos Santos (Alfredão) que ensinou o oficio de sineiro para José Gomes de Souza - "Zé Prego" (1920-1987) que, por sua vez, transmitiu para seu filho José Antônio de Moraes e Souza - "Zé Tachinha" (1960-2011). "Zé Tachinha", como era popularmente conhecido, ensinou o ofício para Rafael Lino Rosa, atual provedor da Venerável Irmandade do Senhor Bom Jesus dos Passos:

Em 1997 retornei a Goiás depois de um longo período. Havia vindo quando criança e nunca mais voltei. Vim para a Semana dos Passos e assisti pela primeira vez a Procissão do Senhor dos Passos. Estávamos na procissão e Zé Tachinha me chamou para ajudar a carregar a cruz da irmandade. Eu fui. Como ele estava rezando alto o terço eu o ajudei. Ali nasceu uma amizade. [...] Coincidentemente eu estava no Domingo dos Passos cedo na Igreja de São Francisco de Paula e faleceu um irmão. Zé Tachinha me pediu para dar o sinal. Ele me explicou, eu subi na sineira e executei. Na segunda na procissão da Trasladação da imagem do Senhor dos Passos toquei novamente o sino, desta vez diferente: puxado na corda. Era para eu embalar o sino e depois, de uma vez, colocar o peso do meu corpo para que o sino batesse rápido. Muita gente achou ruim um 'forasteiro' tocar o sino. [...] Comecei a participar do calendário de festas da Cidade de Goiás com frequência. Zé Tachinha me ensinou a tocar defunto homem, mulher e anjinho. Anjinho eu nunca toquei e nem quero. É muito dolorido, muito triste. 0 mais triste dos sinais. Aprendi a receber a procissão na igreja tocando o sino. 0 toque para irmão dos Passos falecido é três pancadas. No grande. Uma só isolada. Duas mais juntas: 1...1.1. 1...1.1. 1...1.1. A gente dá o sinal e conta 1, 2, 3 na cabeça e repete. Para mulher, para irmã dos Passos, a gente começa 
no sino menor. O mesmo compasso. Aí intercala com o grande. 2...2.2. 2...2.2. 2...2.2. e 1...1.1. 1...1.1. 1...1.1. Onde o 1 é o sino grande e o 2 o sino menor. Anjinho é você bimbalhar alegremente o sino pequeno, numa alegria, num frenesi. Aí para de uma vez. E dá três pancadas no grande. 1...1.1. 1...1.1. 1...1.1. E repete sete vezes. ${ }^{17}$

O depoimento do atual sineiro dos Passos demonstra um processo de aprendizado, mesclado pela observação e pela prática, a partir do contato com um sineiro experiente. Dominar a "linguagem dos sinos" consistiu em deixar de ser um "forasteiro" e se inserir na comunidade local por meio de um vocabulário de motivos compartilhado, tornando-se mediador por meio dos sons, dos gestos, do intervalo entre som e silêncio que demarca a paisagem sonora vilaboense.

O sineiro maneja um repertório mobilizado pela cidade, com sotaques singulares. Aciona o imaginário em torno do sino e de seus toques com um enorme poder simbólico, marcador litúrgico e temporal. O tempo dos seres humanos e o tempo da Divindade, da vida e da morte, as horas... "chora" e "geme" de tristeza e "dobra" de alegria. Há quase 300 anos os sineiros dominam saberes responsáveis pelas ressonâncias (auto)biográficas e patrimoniais na paisagem sonora e afetiva dos vilaboenses, respondendo à pergunta lançada como título deste artigo.

\section{Referências}

ABREU, Martha. Festas religiosas no Rio de Janeiro: perspectivas de controle e tolerância no século XIX. Estudos Históricos, Rio de Janeiro, Fundação Getúlio Vargas, v. 7, n. 14, p. 183-203, 1994. Disponível em: http:/ / bibliotecadigital.fgv.br/ojs/index.php/reh / article/view/1985. Acesso em: 10 nov. 2019.

BERTRAN, Paulo. Cidade de Goiás - Patrimônio da Humanidade: origens. Brasília e São Paulo: Ed. Verano e Takano, 2002.

17 Entrevista com Rafael Lino Rosa, Cidade de Goiás, 12 de novembro de 2019.
BOURDIEU, Pierre. 0 poder simbólico. 2a ed. Rio de Janeiro: Bertrand Brasil, 1998.

BRASIL. IPHAN. Dossiê Toque dos sinos e o ofício de sineiro em Minas Gerais. Brasília: Instituto do Patrimônio Histórico e Artístico Nacional, 2009.

BRITTO, Clovis Carvalho; ROSA, Rafael Lino. Mestra e Guia: a Catedral de Sant'Ana e as devoções de Darcília Amorim. Goiânia: Espaço Acadêmico, 2017.

BRITTO, Clovis Carvalho; ROSA, Rafael Lino (Orgs.). Nos Passos da Paixão: A Irmandade do Senhor Bom Jesus dos Passos em Goiás. Goiânia: PUC-GO/Kelps, 2011.

BRITTO, Clovis Carvalho; PRADO, Paulo Brito do. PRADO, Paulo Brito do. A economia simbólica da Paixão vilaboense. In: BRITTO, Clovis Carvalho; ROSA, Rafael Lino (Orgs.). Nos Passos da Paixão: A Irmandade do Senhor Bom Jesus dos Passos em Goiás. Goiânia: PUC-GO/Kelps, 2011. p. 102-128.

BRITTO, Clovis Carvalho. Catolicismo popular e espaço público no culto ao Senhor Bom Jesus dos Passos na Cidade de Goiás (séculos XVIII e XIX). In: BRITTO, Clovis Carvalho; ROSA, Rafael Lino. (Orgs.). Nos Passos da Paixão: A Irmandade do Senhor Bom Jesus dos Passos em Goiás. Goiânia: PUC-GO/Kelps, 2011. p. 55-84.

CAMPOS, Adalgisa Arantes. Aspectos da Semana Santa através do estudo das irmandades do Santíssimo Sacramento: cultura artística e solenidades (Minas Gerais séculos XVII ao XX). Revista Barroco, Belo Horizonte, v. 19, p. 71-88, 2005. Disponível em: http://www.cbha.art.br/coloquios/2004/textos/01_ adalgisa.pdf. Acesso em: 2 nov. 2019.

CORALINA, Cora. 0 tesouro da Casa Velha. São Paulo: Global, 1989.

CORALINA, Cora. Poemas dos becos de Goiás e estórias mais. 20ạ ed. São Paulo: Global, 2001.

CORALINA, Cora. villa Boa de Goyaz. 2a ed. São Paulo: Global, 2003.

DI GUIMARÃES, Juruena. De binóculo. Goiânia: Kelps, 2000.

FERREIRA, Luiza de Camargo. Do baú de Luiza. Goiânia: Formato, 2003. 
GONÇALVES, José Reginaldo Santos. Antropologia dos objetos: coleções, museus e patrimônios. Rio de Janeiro: DEMU, 2007.

LACERDA, Regina. Vila Boa: história e folclore. 2a ed. Goiânia: Oriente, 1977.

LEFEBVRE, Gaspar. Missal Quotidiano e Vesperal. Bruges: Desclée, De Brouwer e Cia, 1951.

MATTOS, Raymundo José da Cunha. Chorographia histórica da Província de Goyaz. Goiânia: Governo de Goiás, 1979.

MORAES, Cristina de Cássia Pereira. Do corpo místico de Cristo: irmandades e confrarias na Capitania de Goiás (1736-1808). Goiânia: FUNAPE, 2012.

MORAES, Cristina de Cássia Pereira. Religiosidade e sociabilidade entre os confrades do Patriarca São José. In: QUADROS, Eduardo Gusmão de; SILVA, Maria da Conceição; MAGALHÃES, Sônia Maria de. Cristianismos no Brasil Central: história e historiografia. Goiânia: Editora da UCG, 2008. p. 47-70.

PASSOS, Lindolpho Emiliano dos. Goiás de ontem: memórias militares e políticas. Goiânia: Edição do autor, 1986.

RAMOS JUBÉ, Antônio Geraldo. Lira vilaboense. Goiânia: CERNE, 1984.

ROSA, Rafael Lino. Dor e sacrificio: o imaginário religioso católico vilaboense. 2016. 238 f. Tese (Doutorado em Ciências da Religião), Programa de PósGraduação em Ciências da Religião, Pontifícia Universidade Católica de Goiás, Goiânia, 2016.

ROSA, Rafael Lino. Irmandade dos Passos e a formação da identidade cultural da Cidade de Goiás. 2012. 68 f. Dissertação (Mestrado em Ciências da Re- ligião), Programa de Pós-Graduação em Ciências da Religião, Pontifícia Universidade Católica de Goiás, Goiânia, 2012.

RUIZ, Castor Bartolomé. Os paradoxos do imaginário. São Leopoldo: UNISINOS, 2004.

SCHAFER, Murray. A afinação do mundo. São Paulo: Editora Unesp, 2001.

SIQUEIRA, Guilherme Antônio. Alegorias em cena: uma leitura iconográfica dos elementos artísticos da Irmandade do Senhor Bom Jesus dos Passos e da Igreja de São Francisco de Paula. In: BRITTO, Clovis Carvalho; ROSA, Rafael Lino. (Orgs.). Nos Passos da Paixão: A Irmandade do Senhor Bom Jesus dos Passos em Goiás. Goiânia: PUC-GO/Kelps, 2011. p. 129-161.

SOUZA, Ana Guiomar Rêgo. Villa Boa de Goyaz: uma outra história contada em prosa, versos e sons. ArtCultura, Uberlândia, Universidade Federal de Uberlândia, v. 17, n. 30, p. 179-197, jan-jun. 2015. Disponivel em: http://www.seer.ufu.br/index.php/artcultura/ article/view/34821/18427 Acesso em: 2 nov. 2019.

SOUZA FILHO, Eduardo Henrique de. Nos tempos de Goyaz: crônicas e poemetos. Goiânia: UNIGRAF, 1981.

TAMASO, Izabela. Em nome do patrimônio: representações e apropriações da cultura na Cidade de Goiás. 2007. 787 f. Tese (Doutorado em Antropologia), Programa de Pós-Graduação em Antropologia, Universidade de Brasília, Brasília, 2007.

TELES, José Mendonça. Vida e obra de Silva e Souza. Goiânia: UFG, 1998.

Recebido em: 15.11 .2019

Revisado em: 10.05.2020

Aprovado em: 12.05 .2020

Clovis Carvalho Britto é doutor em Museologia pela Universidade Lusófona de Humanidades e Tecnologias, Lisboa. Professor no curso de Museologia e no Programa de Pós-Graduação em Ciência da Informação (PPGCINF) da Universidade de Brasília (UnB) e no Programa de Pós-Graduação em Museologia da Universidade Federal da Bahia (UFBA). Bolsista de Produtividade em Pesquisa (PQ-2) do Conselho Nacional de Desenvolvimento Científico e Tecnológico (CNPq).

E-mail: clovisbritto@unb.br

Rafael Lino Rosa é doutor e mestre em Ciências da Religião pela Pontifícia Universidade Católica de Goiás (PUCGO). Professor da Secretaria de Estado da Educação de Goiás (SEDUC). E-mail: barao.lino@hotmail.com 